\title{
Concepções de gestão escolar pós-LDB O gerencialismo e a gestão democrática
}

\author{
Givanildo da Silva* \\ Alex Vieira da Silva \\ INALDA MARIA DOS SANTOS
}

\begin{abstract}
RESUMO: O texto apresenta discussões sobre os modelos de gestão escolar instaurados no período pós - LDB, de 1996 e suas implicações para o cenário educacional. As reflexões possibilitaram compreender que a gestão escolar democrática está em segundo plano nas práticas educativas, em detrimento da gestão gerencialista apresentada nas políticas educacionais, preconizada pelos organismos multilaterais e confirmada pelo Estado avaliador.
\end{abstract}

Palavras-chave: Gestão escolar. Gerencialismo. Gestão democrática.

\section{Conceptions of school management - after the Law on the Directives and Bases for Education (LDB) \\ Managerialism and democratic management}

\begin{abstract}
This text presents discussions on the models of school management installed in the period after the LDB, de 1996 and the implications for the area of education. The reflections enable us to understand that democratic school management takes second place in educational practices, behind the managerialist manage-
\end{abstract}

* Doutorando em Educação do Programa de Pós-graduação em Educação da Universidade Federal da Paraíba (PPGE/UFPB). Alagoas/AL - Brasil. E-mail: <givanildopedufal@gmail.com>.

** Mestrando em Educação do PPGE/UFPB. Tem experiência profissional como docente na educação básica no ensino fundamental I (professor polivalente). Realiza estudos na linha de pesquisa Gestão, Avaliação e Políticas Públicas da Educação. Alagoas/AL - Brasil. E-mail: <alexpedufal@gmail.com>.

*** Doutora em Educação. Professora associada do Centro de Educação no curso de Pedagogia e no curso de Mestrado do Programa de Pós-Graduação em Educação da UFAL e participa na condição de líder e pesquisadora do Grupo de Pesquisa Gestão e Avaliação Educacional (GAE/UFAL). Atuou como Vice-Diretora da Associação Nacional de Política e Administração da Educação - ANPAE, seção Alagoas no período de 2013-2015. Alagoas/AL - Brasil. E-mail: <inaldasantos@uol.com.br>. 
ment presented in educational policies, as recommended by multilateral organizations and confirmed by the evaluating State.

Key words: School management. Managerialism. Democratic management.

\title{
Conceptos de gestión escolar posteriores a la LDB
}

\author{
O gerencialismo y la gestión democrática
}

RESUMEN: El texto presenta discusiones sobre los modelos de gestión escolar implementados en el periodo posterior a la LDB, de 1996 y sus implicaciones en el escenario educativo. Las reflexiones permitieron comprender que la gestión escolar democrática está en segundo plano en las prácticas educativas, en detrimento de la gestión gerencialista presentada en las políticas educativas, preconizada por los organismos multilaterales y confirmada por el Estado evaluador.

Palabras clave: Gestión escolar. Gerencialismo. Gestión democrática.

\section{Conceptions de gestion scolaire post-LDB}

Le managérialisme et la gestion démocratique

RÉSUMÉ: Ce texte présente les débats autout des modéles de gestion établis dans la période post-LDB, de 1996, et leurs conséquences dans le contexte éducationnel. Les réflexions permettent de comprendre que la gestion scolaire démocratique reste en arriére- plan dans les pratiques éducatives, au détriment de la gestion managériale, présentée par les politiques éducatives, préconisée par les organismes multilatéraux et validée par l'Etat évaluateur.

Mots-clés: Gestion scolaire. Managérialisme. Gestion démocratique. 


\section{Introdução}

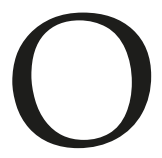

texto apresenta discussões sobre os modelos de gestão escolar instaurados no período pós - LDB/1996 e suas implicações para o cenário educacional. Tem como paradigmas a gestão gerencial e a democrática como modelos antagônicos, configurando-se em diferentes concepções de educação. As reflexões perpassam pelos princípios basilares de cada uma das concepções, assim como apresenta a defesa da gestão democrática nas práticas escolares.

As concepções de gestão escolar que permeiam as práticas educativas são paradigmas que emergem em meio às tensões e aos desafios postos no contexto social. Após vinte anos de aprovação da Lei de Diretrizes e Bases da Educação Nacional (Lei no 9.394, de 1996), as políticas educacionais possibilitaram mudanças estruturais no cenário organizacional das atividades educativas, assim como transformaram os princípios basilares da gestão democrática em ações da gestão gerencial, apresentando sentidos opostos aos preconizados pelos movimentos de educadores em meados da década de 1980.

O processo da globalização contribuiu para a existência de acordos nacionais e internacionais, os quais tinham o Estado e as políticas educativas como significativos espaços para a concretização de ideais mercadológicos e competitivos (DALE, 2006). Em convergência com esse argumento, Vieira (2012) lembra que a globalização possibilitou três ações decisivas para as mudanças de paradigmas no contexto social e na educação. São elas: a) o processo de comunicação e informação; b) a presença dos organismos multilaterais nas políticas públicas; e c) a reestruturação do papel do Estado.

Nesse cenário, Roger Dale (2006, p.78) salienta que

[...] a reforma da governação tem sido na última década, e parece provável que continue a ser, o principal meio de reformar a educação. Numa era que parece caracterizar-se por uma ambição de transformar, em vez de cada vez mais melhorar os sistemas e práticas da educação, a reforma da governação constitui o primeiro passo necessário, quer envolva mudanças no controle da pedagogia, quer revisões dos conceitos de tempo e espaços educativos.

Assim, as reformas oriundas da reestruturação do Estado viabilizaram mecanismos favoráveis à produtividade, à eficiência e à eficácia, justificados pela modernização e pelas novas roupagens que a sociedade incorpora em suas práticas culturais, sociais, políticas e educacionais. De acordo com Casassus (1995a), as mudanças ocasionadas pelas reformas educacionais levaram à: a) desconcentração e centralização dos sistemas; b) introdução de tecnologias de informação na gestão dos sistemas; c) redistribuição de gastos educacionais e privatização; d) redistribuição de responsabilidades e racionalização dos recursos humanos; e) desregulamentação dos sistemas de ensino.

Nesse contexto, a desconcentração evidencia o poder dos idealizadores de programas e projetos na esfera social/educacional. No âmbito da educação, a descentralização 
é vista como um princípio que dimensiona poder para os agentes no interior da escola, quando, na verdade, apenas desconcentra as atividades, para que a comunidade escolar responsabilize-se e cumpra as normatizações dos programas. Assim sendo, "o processo de descentralização atualmente em desenvolvimento no sistema educacional não foi resultado das conquistas democráticas por parte dos movimentos sociais, embora reconheçamos a sua importância nessa dinâmica" (CABRAL NETO; CASTRO, 2011, p. 751).

A descentralização, no contexto da reforma gerencial, é um mecanismo de desconcentração, viabilizando estratégias para que a comunidade escolar e local responsabilizem-se para atividades de gestão e organização, incluindo o financiamento de projetos desenvolvidos pela escola. Desse modo, algumas características são apresentadas, pelos idealizadores, como referência para se viver a descentralização na escola, destacando-se "mais democracia; mais eficiência no trabalho educativo; mais recursos e participação da comunidade; maior qualidade na educação" (CASASSUS, 1995, p. 41).

Essas características são relevantes, no entanto, os objetivos pretendidos pelo Estado é que a comunidade local e a escolar assumam a responsabilização por criar estratégias, para conseguir efetivar a educação com recursos (financeiros, humanos e materiais) mínimos. A democracia pretendida não corresponde à igualdade de oportunidade para todos, mas, a participação dos diferentes segmentos no cumprimento de atividades educativas; a eficiência corresponde, principalmente, à racionalização dos recursos, em que se deve fazer mais com menos. Mais recursos referem-se à participação da sociedade civil (empresários) na contribuição da oferta de uma educação pública, assim como à da própria comunidade escolar com estratégias para conseguir recursos financeiros e voluntários para a escola (CASASSUS, 1995).

No âmbito da escola pública, a prática da descentralização do poder é possível na medida em que as posturas vivenciadas sejam de caráter participativas e democráticas, bem como os principais objetivos sejam na perspectiva da humanização e colaboração dos ideais educacionais propostos através de planejamentos coletivos. Com essa característica, "é impossível construir uma sociedade democrática nos moldes de uma escola autoritária e, por isso, será impossível a uma escola autoritária ensinar os homens a viverem e convirem num processo democrático" (RODRIGUES, 1996, p. 62).

\section{Gerencialismo e gestão democrática}

A concepção gerencialista de administração pública surge em meio à crise da governabilidade e as resistências de consolidar um Estado de bem-estar social em diversos países do mundo, por volta de 1980, sendo uma alternativa para o Estado direcionar suas funções à sociedade e ao mercado, assim como consolidar políticas que beneficiem aos empresários e à classe dominante. A gestão gerencialista passou a representar 
os anseios do governo, cujas raízes estão na concepção política do neoliberalismo. No Brasil, segundo Paula (2005), esse modelo de gestão pública ganhou força na década de 1990, com o debate da reforma gerencial do Estado e o desenvolvimento da administração pública gerencial.

A crise do nacional-desenvolvimentismo e as críticas ao patrimonialismo e autoritarismo do Estado brasileiro estimularam a emergência de um consenso político de caráter liberal que se baseou na articulação das seguintes estratégias: a estratégia do desenvolvimento dependente e associado; as estratégias neoliberais de estabilização econômica; e as estratégias administrativas dominantes no cenário das reformas orientadas para o mercado. Essa articulação sustentou a formação da aliança social-liberal, que levou o Partido da Social-Democracia Brasileira (PSDB) ao poder (PAULA, 2005, p. 38).

A consolidação da administração pública gerencialista foi pensada para todas as esferas da sociedade, viabilizando estratégias que levassem o Estado a ser o idealizador de políticas públicas e os setores sociais, público e privado, se responsabilizassem por sua efetivação. As reformas implementadas tiveram caráter dominante e contribuíram para a exclusão, uma vez que o mercado (poder de compra) era o referencial para as experiências planejadas.

As principais estratégias idealizadas para consolidar esse modelo de gestão, de acordo com Paula (2005), foram as seguintes: ao Estado cabia fiscalizar, fazer as legislações e formular políticas; as empresas e a sociedade civil tinham o papel de contribuir nas atividades de caráter competitivo, uma vez que estão a serviço da população mais carente (saúde, educação e assistência social); as atividades auxiliares e de apoio, como limpeza, vigilância, transporte e outros serviços, deviam ser submetidos à licitação pública e contratadas por terceiros (PAULA, 2005).

Para Hypólito (2008), uma das principais dimensões da gestão gerencialista é a relação público e privado, na qual a parceria é a privatização. Para o autor, a vivência da privatização é entendida como venda direta das posses públicas para os setores privados/comerciais, troca de responsabilidades do público para o privado e desresponsabilização do Estado por questões básicas para a população. Assim, Hypólito (2008, p. 69) aponta que "esses discursos penetram o gerencialismo em diferentes áreas e setores, transformando várias formas de senso comum e criando novas concepções para estado, mercado, economia, escola pública e administração pública”. Para Cabral Neto (2009, p. 172), a reforma gerencial apresenta no seu conjunto de objetivos "a desburocratização, a descentralização, a transparência, a ética, o profissionalismo, a competitividade e o enfoque no cidadão". É válido apontar que o enfoque no cidadão é numa perspectiva em que cada um é responsável por conquistar seus interesses, sem ter o Estado como referência para os direitos sociais. 
De acordo com Cabral Neto e Castro (2011), as principais características da concepção de gestão pública gerencialista são a perspectiva hegemônica, na qual se consolidam ideais burgueses, tendo a população que se adequar às condições implementadas e buscar alternativas para competir e conquistar espaços na sociedade, uma vez que a intenção do Estado consiste não só em diminuir a intervenção na economia, mas também em suas próprias dimensões. Assim, os autores assinalam que

O ponto de apoio da reforma gerencial é a busca da eficiência, pela redução e
controle dos gastos públicos, pela demanda de melhor qualidade de serviços
públicos, pela descentralização administrativa, concedendo maior autonomia às
agências e departamentos. Há preocupação, portanto, com o produto em detri-
mento dos processos (CABRAL NETO; CASTRO, 2011, p. 748)

A ênfase desse modelo de gestão pública é a descentralização das responsabilidades e a busca de mecanismos de eficiência e eficácia, tendo como pressuposto o controle do Estado. Todas as dimensões da sociedade são influenciadas e a educação, segundo Cabral Neto e Castro (2011), é um campo significativo para consolidar estratégias políticas de caráter focalizador, uma vez que há ênfase na participação e autonomia nas escolas. No entanto, "a participação se metamorfoseia em uma técnica de gestão propiciadora de coesão, despolitizando, assim, o processo de participação dos sujeitos sociais na formulação, implementação e avaliação da política" (CABRAL NETO; CASTRO, 2011, p. 751).

A educação, a partir da década de 1990, vem sendo um espaço para projetos e programas na perspectiva de gestão gerencial, com o que se defende a gestão inovadora no intuito de melhorar a qualidade do ensino, tendo a descentralização e a autonomia como mecanismos básicos para alcançar esse objetivo. Para Cabral Neto (2009), a defesa por uma gestão com ênfase na gerência escolar encontra-se presente nas principais políticas educacionais, assim como nos documentos oficiais que regulamentam a educação na América Latina, tendo como objetivo basilar a gestão escolar e a qualidade da educação nos países cujos resultados das avaliações internacionais não são significativos.

A defesa por uma gestão pública gerencial está fundamentada na concepção política neoliberal e na visão do Estado mínimo, sendo a comunidade escolar responsável pelas atividades que contribuam para a gestão, a organização e o financiamento da educação. Assim, esse modelo inclui "a defesa da responsabilização dos gestores e o protagonismo dos pais, dos alunos e dos professores nas tomadas de decisões da escola, aspectos inerentes à nova gestão pública" (CABRAL NETO, 2009, p. 198).

O mecanismo de participação dos diferentes segmentos como responsáveis pela escola seria importante se a sua existência fosse a perspectiva de uma gestão colegiada, na tomada de decisão e na cobrança por uma educação democrática, inclusiva e de boa qualidade. No entanto, "a descentralização se reconfigura em um crescente processo de desconcentração de funções e responsabilidades [...], a participação transforma-se em 
técnica de gestão que funciona como fator de coesão e consenso [...], e a autonomia é concebida como consentimento para construir" (CABRAL NETO, 2009, p. 201).

Estudos (HYPÓLITO, 2008; PAULA, 2005; CABRAL NETO E CASTRO, 2011; CABRAL NETO, 2009) apontam que a gestão gerencial vai de encontro com as perspectivas defendidas pela gestão democrática, uma vez que não favorece a educação pública de boa qualidade e intensifica a racionalização dos recursos e a responsabilização da comunidade escolar e local pelas atividades financeiras. $\mathrm{O}$ aspecto do racionamento dos recursos financeiros na escola torna-se um mecanismo defendido pela gestão pública gerencial, uma vez que as próprias comunidades em que as escolas estão inseridas devem organizar-se para conseguir recursos adicionais para suas atividades. Essa ação contribui para a desresponsabilização da instituição pública e favorece a má qualidade da educação, situação que se perpetua há muitos anos na história da educação pública brasileira.

A gestão democrática, no Brasil, tem como referência a década de 1960, quando a sociedade organizou-se pelas reformas do País. Os movimentos populares e sociais, o movimento sindical, as pastorais sociais, os partidos políticos de esquerda e centro-esquerda e as Organizações Não-Governamentais tiveram relevância no processo histórico, nas conquistas pela efetivação dessa concepção de gestão pública. De acordo com Paula (2005, p. 39), o projeto de sociedade democrática visava:

A implementação de um projeto político que procura ampliar a participação dos atores sociais na definição da agenda política, criando instrumentos para possibilitar um maior controle social sobre as ações estatais e desmonopolizando a formulação e a implementação das ações públicas.

Nesse contexto, diversas foram as propostas populares para consolidar a gestão democrática nas esferas da sociedade brasileira, uma vez que a participação é o principal mecanismo para efetivar as conquistas sociais. A gestão democrática é um desafio na sociedade brasileira, visto que a sua história política, social e cultural é marcada pelas ações de coronelismo, mandonismo, clientelismo e desfavorece atitudes de descentralização do poder, participação nas decisões e autonomia para direcionar as políticas por caminhos que favoreçam a todos.

Na atualidade, a gestão democrática é defendida por estudiosos da educação (BRUEL, 2010; CASTRO, 2008; CURY, 2005; DALBERIO, 2009; DOURADO, 2011; FRANÇA, 2009; HORA, 1994; LIBÂNIO, 2004; LÜCK, 2010; PARO 2007; entre outros) que manifestam a relevância dessa concepção de gestão na escola pública e nas esferas sociais. No âmbito da legislação, a gestão democrática é legalizada, em primeira instância, pela CF/1988, em seguida, pela lei que rege a organização da educação brasileira LDB (9.394/96) e os Planos Nacional, Estadual e Municipal de Educação.

A atual Carta Magna (CF/1988), que rege a sociedade brasileira, deixa explícita a concepção de gestão que deve ser vivenciada no âmbito social. No campo educacional, 
esta concepção estabelece que a gestão democrática efetive-se com a participação e com os princípios estabelecidos em cada instituição na forma da lei. No artigo 206 da CF/1988, a educação é baseada por princípios_que nortearão as práticas cotidianas, de modo que:

Art. 206. O ensino será ministrado com base nos princípios:

I - igualdade de condições para o acesso e permanência na escola;

II - liberdade de aprender, ensinar, pesquisar e divulgar o pensamento, a arte e o saber;

III - pluralismo de ideias e de concepções pedagógicas, e coexistência de instituições públicas e privadas de ensino;

IV - gratuidade de ensino público nos estabelecimentos oficiais;

V - valorização dos profissionais de ensino, garantindo, na forma da lei, planos de carreira para o magistério público, com piso salarial profissional e ingresso exclusivamente por concurso público de provas e títulos, assegurado regime jurídico único para todas as instituições mantidas pela União;

VI - gestão democrática de ensino público, na forma da lei;

VII - garantia de padrão de qualidade;

VIII - piso salarial profissional nacional para os profissionais da educação da educação escolar pública, nos termos da lei federal. (BRASIL, 1988).

Com base nesse artigo, nota-se que a educação é vista, teoricamente, como uma dimensão significativa para possibilitar autonomia aos agentes envolvidos, bem como uma importante mediadora para uma possível transformação social. As ações norteadoras, que se vinculam às práticas educativas, são a igualdade, a liberdade e o pluralismo de expressão. Nessa perspectiva, “a Constituição de 1988 avançou um pouco no sentido da melhor caracterização no campo do ensino" (TAVARES, 2003, p. 56).

Com a legislação em vigor, existem alguns desafios para vivenciar novas posturas que despertem para a vivência da gestão democrática, pois é preciso as "efetivar em práticas concretas nos sistemas e no chão da escola" (CURY, 2005, p. 15). A atuação dos princípios dessa concepção de gestão requer mudanças de paradigmas que estabeleçam uma ruptura com as práticas até então vividas. Assim, é importante questionar: como romper com posturas que foram inculcadas no cotidiano da sociedade e no contexto escolar? A aprovação da CF/1988 resultou de projetos e reivindicações de grupos organizados, que buscaram romper com as ações autoritárias e a opressão na sociedade brasileira, porém esses grupos eram a mínima parcela da sociedade, sendo a maioria submissa às práticas autoritárias e hierárquicas.

A aprovação da CF/1988 foi um marco significativo para toda a sociedade e, em especial, para a escola pública, que se vê na possibilidade de mudanças em meio à sua organização, sendo o gestor um dos principias agentes que precisa mudar suas ações e 
dividir responsabilidades, percebendo que seu papel não é mais o de ordenar e fiscalizar, mas de inserir-se na comunidade escolar e possibilitar a divisão das atividades, descentralizando o poder no contexto escolar. É pertinente mencionar que a experiência da gestão democrática não foi aceita por todos com passividade, especialmente, por aqueles que estavam no poder há muito tempo e não conseguiam perceber que a verticalidade $^{1}$ estava se transformando em horizontalidade ${ }^{2}$ (SPÓSITO, 2005).

Na pauta das reivindicações da sociedade civil, a eleição de representantes das instituições educativas norteavam as principais ações para uma mudança de paradigma de gestão, assim como a constituição de órgãos representativos que se configurassem como controle social nos processos de decisões (MINTO, 2010). A partir dessa nova configuração, a descentralização surge como mecanismo importante para a contribuição dos diversos segmentos que formam a unidade educativa, sendo o gestor escolar o responsável pela prática desses órgãos no contexto da escola pública. No entanto, a conceituação defendida na gestão democrática é uma descentralização oposta à descentralização da gestão gerencial.

A partir de 1996, foi aprovada no Congresso Federal, especificamente, no dia 20 de dezembro de 1996, a Lei de Diretrizes de Bases da Educação Nacional. Com essa legislação, a educação brasileira apresenta alguns avanços em sua organização, especialmente porque é elaborada a partir dos pressupostos da CF/1988, em que a gestão democrática é um dos principais elementos de mudança no contexto da sociedade brasileira.

Assim, através da LDB/1996, as instituições públicas passam a ter relativa autonomia ${ }^{3}$ quanto à organização e às funções da equipe gestora, em especial, nas práticas pedagógica, administrativa e financeira. Essas funções são ressignificadas na legislação atual e sinalizam a interação entre a equipe escolar, de modo que sejam vivenciados alguns mecanismos da gestão democrática, entre eles a descentralização do poder, a

1 Verticalidade é um modelo de gestão em que a hierarquia é tida como receita e todos são submissos ao gestor. As atividades são todas provenientes das exigências feitas pelo gestor e os sujeitos envolvidos devem submeter-seàs suas solicitações sem questionamentos (SPÓSITO, 2005).

2 Horizontalidade é um modelo de gestão em que há significativas contribuições de todos os envolvidos, sendo o gestor o mediador das práticas educacionais e os demais agentes têm responsabilidade para o sucesso das atividades realizadas no cenário educacional (SPÓSITO, 2005).

3 "A autonomia é um conceito relacional (somos sempre autónomos de alguém ou de alguma coisa) pelo que a sua acção se exerce sempre num contexto de interdependência e num sistema de relações. A autonomia é também um conceito que exprime um certo grau de relatividade: somos mais, ou menos, autónomos; podemos ser autónomos em relação a umas coisas e não o ser em relação a outras. A autonomia é, por isso, uma maneira de gerir, orientar, as diversas dependências em que os indivíduos e os grupos se encontram no seu meio biológico ou social, de acordo com as suas próprias leis." (BARROSO, 1996, p. 17) 
participação e a autonomia. A organização escolar assume postura diferenciada e as ações que são enfatizadas na LDB/1996 destacam a elaboração coletiva de uma proposta pedagógica que vise à realidade e às demandas de cada unidade escolar, com o propósito de contribuir para significativa participação e vivências de experiências, que proporcionem uma educação de boa qualidade com oportunidades para todos.

Nessa perspectiva, a LDB/1996 avançou satisfatoriamente para a concepção de educação que possibilite a todos os envolvidos no espaço escolar ser parte integrante das ações e decisões no âmbito educacional. No artigo $3^{0}$ da LDB, é enfatizado que a educação será ministrada a partir de princípios que deverão estar presentes em meio às vivências dos envolvidos no contexto educacional, reproduzindo os mesmos princípios postos na $\mathrm{CF} / 1988$.

Os ideais da educação expostos na LBD/1996 reportam as ações mencionadas na CF/1988, estabelecendo uma concepção de educação pautada nos princípios democrático, inclusivo e participativo. Os aspectos destacados dizem respeito à uma educação que possibilite oportunidades a todos os envolvidos e expresse, sob a forma da lei, a gestão democrática, configurado pelo respeito ao próximo, liberdade de opinião e valorização dos agentes do cotidiano educacional. Para melhor destacar o papel dos sujeitos sociais envolvidos na educação, a partir da legislação, é relevante reportar-se ao artigo 14 da mesma lei, que define as normas da gestão democrática no espaço escolar e afirma que a educação básica pública deve vivenciar essa concepção de gestão em seu cotidiano, contribuindo para a participação dos profissionais da educação na elaboração do projeto político pedagógico e na participação da comunidade escolar e local em conselhos escolares (BRASIL, 1996).

Assim, as diretrizes da LDB/1996 em relação à participação de todos que compõem a unidade educativa veiculam mecanismos da própria comunidade escolar e local no planejamento do projeto pedagógico, a fim de melhorar a qualidade da realidade educacional, por meio de participação e de processos decisórios, sob a ótica de diversos segmentos. Outro aspecto significativo é a ênfase nos conselhos escolares, na forma de controle social, numa perspectiva de deliberação das práticas escolares, propiciando maior autonomia e descentralização das ações planejadas pela comunidade escolar.

Após a apresentação das diferentes concepções de gestão pública e escolar, apresenta-se um quadro síntese das principais características de cada uma (gerencial e democrática), para melhor compreensão de suas divergências. 


\section{Quadro 1 - Fundamentos da gestão gerencial e democrática}

\begin{tabular}{|c|c|c|}
\hline & $\begin{array}{l}\text { Administração Pública } \\
\text { Gerencial }\end{array}$ & $\begin{array}{l}\text { Administração Pública } \\
\text { Societal/Democrática }\end{array}$ \\
\hline Origem & $\begin{array}{l}\text { Movimento internacional } \\
\text { pela reforma do Estado, que } \\
\text { se iniciou nos anos } 1980 \text { e } \\
\text { baseia-se principalmente } \\
\text { nos modelos inglês e } \\
\text { estadunidense. }\end{array}$ & $\begin{array}{l}\text { Movimentos sociais } \\
\text { brasileiros, que tiveram } \\
\text { início nos anos } 1960 \text { e } \\
\text { desdobramentos nas três } \\
\text { décadas seguintes. }\end{array}$ \\
\hline Projeto político & $\begin{array}{l}\text { Enfatiza a eficiência } \\
\text { administrativa e baseia- } \\
\text { se no ajuste estrutural, } \\
\text { nas recomendações dos } \\
\text { organismos multilaterais } \\
\text { internacionais e no } \\
\text { movimento gerencialista. }\end{array}$ & $\begin{array}{l}\text { Enfatiza a participação } \\
\text { social e procura estruturar } \\
\text { um projeto político que } \\
\text { repense o modelo de } \\
\text { desenvolvimento brasileiro, } \\
\text { a estrutura do aparelho de } \\
\text { Estado e o paradigma de } \\
\text { gestão. }\end{array}$ \\
\hline $\begin{array}{l}\text { Dimensões estruturais } \\
\text { enfatizadas na gestão }\end{array}$ & $\begin{array}{l}\text { Dimensões econômico- } \\
\text { financeira e institucional- } \\
\text { administrativa }\end{array}$ & Dimensão sociopolítica \\
\hline $\begin{array}{l}\text { Organização administrativa } \\
\text { do aparelho do Estado }\end{array}$ & $\begin{array}{l}\text { Separação entre as } \\
\text { atividades exclusivas e não } \\
\text { exclusivas do Estado nos três } \\
\text { níveis governamentais. }\end{array}$ & $\begin{array}{l}\text { Não há uma proposta para a } \\
\text { organização do aparelho do } \\
\text { Estado e enfatiza iniciativas } \\
\text { locais de organização e } \\
\text { gestão pública. }\end{array}$ \\
\hline $\begin{array}{l}\text { Aberturadas instituições } \\
\text { políticas à participação social }\end{array}$ & $\begin{array}{l}\text { Participativo no nível do } \\
\text { discurso, mas centralizador } \\
\text { no que se refere ao processo } \\
\text { decisório, à organização } \\
\text { das instituições políticas e } \\
\text { à construção de canais de } \\
\text { participação popular. }\end{array}$ & $\begin{array}{l}\text { Participativo no nível das } \\
\text { instituições, enfatizando a } \\
\text { elaboração de estruturas } \\
\text { e canais que viabilizem a } \\
\text { participação popular. }\end{array}$ \\
\hline Abordagem de gestão & $\begin{array}{l}\text { Gerencialismo: } \\
\text { enfatiza a adaptação } \\
\text { das recomendaçôes } \\
\text { gerencialistas para o setor } \\
\text { público. }\end{array}$ & $\begin{array}{l}\text { Gestão social: enfatiza a } \\
\text { elaboração de experiências } \\
\text { focalizadas nas demandas } \\
\text { do público-alvo, incluindo } \\
\text { questões culturais e } \\
\text { participativas. }\end{array}$ \\
\hline
\end{tabular}

Fonte: Paula (2005, p. 41)

Por meio do quadro 1 (um), pode-se compreender os mecanismos norteadores de cada uma das concepções de gestão. No entanto, é pertinente afirmar que a concepção escolar defendida pelos defensores da escola pública, bem como suas entidades representativas, é a gestão escolar democrática, cujos fundamentos são descentralização, participação e autonomia escolar. 


\section{A defesa da escola pública democrática}

Para a consolidação da gestão democrática na escola pública, é necessária a presença dos diferentes setores da sociedade na construção de um modelo de educação pautado na configuração social, cultural e política do local em que a escola está inserida. Nesse sentido, Lima (2006, p. 31) ressalta que:

[...] a descentralização educativa, a autonomia da escola e a participação democrática assumem um sentido político e cívico incompatível com conotações gerencialistas e neocientíficas. Descentralização e participação não são puras técnicas de gestão eficaz com vista à racionalização e optimização.

A concretização da concepção da gestão democrática expressa-se por meio de órgãos colegiados, que legitimam a participação no cotidiano escolar. Esses órgãos necessitam da presença de diversos segmentos que, muitas vezes, manifestam opiniões divergentes, sendo o objetivo principal oferecer educação de boa qualidade que expresse a concepção de educação presente na legislação e assegure à própria instituição autonomia para vivenciar os projetos estabelecidos por todos, visto que "para que ocorra verdadeira educação na unidade educacional é preciso que nesta haja a autonomia pedagógica e, para que haja esta autonomia pedagógica, será necessária a autonomia administrativa" (SILVA, 1996, p. 54).

Os diversos mecanismos de controle social da instituição escolar são importantes para o rompimento de práticas que centralizam a equipe gestora, que tem o poder de decidir as ações da escola a partir de seu projeto político-pedagógico (PPP), visto que "uma escola mais democrática, é por definição, uma escola mais autónoma e participativa" (LIMA, 2006, p. 31). Assim, considera-se a importância do processo de elaboração do PPP, pois, a partir dessa referência, a escola compromete-se com um determinado tipo de educação, o que resultará em ações favoráveis ao contexto escolar.

Nessa perspectiva, é relevante que se evidencie o papel dos que formam a escola, para mostrar a contribuição de cada um a partir de sua especificidade e das diferentes visões que compõem a unidade escolar. Assim, gestores, pais, professores, profissionais da educação, alunos, comunidade local formam um conjunto sólido para planejar, vivenciar e avaliar as ações para o cotidiano escolar. Para que isso aconteça é relevante compreender a organização e o funcionamento da escola pública a partir de "aspectos políticos, administrativos, financeiros, tecnológicos, culturais, artísticos e pedagógicos" (BRASIL, 2010, p. 667). Ou seja, a escola não é uma instituição isolada da sociedade, mas sua parte, e é importante considerar a realidade, sua história e o público a que atende, para melhor compreensão de seu papel em meio aos trabalhos desenvolvidos.

De acordo com Barroso (1995), a gestão da escola é um trabalho coletivo que demanda conhecimento da realidade em que a instituição está atuando, bem como é 
um exercício que necessita conhecimentos amplos sobre a identidade dos profissionais e as principais características dos pais e da comunidade local. Para uma significativa organização, é preciso que gestores, professores e profissionais que atuam no âmbito escolar sintam-se educadores e tenham conhecimento sobre a prática docente, assim como vejam sua função como um ato educativo. Neste sentido,

[...] numa organização como a escola, a gestão é uma dimensão do próprio acto educativo. Definir objectivos, seleccionar estratégias, planificar, organizar, coordenar, avaliar as actividades e os recursos, ao nível da sala de aula, ou ao nível da escola no seu conjunto, são tarefas com sentido pedagógico e educativo evidentes. Elas não podem, por isso, ser dissociadas do trabalho docente e subordinarem-se a critérios extrínsecos, meramente administrativos (BARROSO, 1995, p. 10).

Assim, é importante que a gestão e a organização da escola estejam intrinsicamente ligadas para que a prática na sala de aula ou, mesmo, o modo de organização dos próprios profissionais sejam coerentes, apresentando as características da escola e defendendo uma concepção de educação que possibilite a emancipação humana, e a ação pedagógica seja um princípio de aprendizagem de práticas que ajudem os sujeitos envolvidos a levá-las para além dos muros da escola (BARROSO, 1995).

No âmbito escolar, há profissionais que contribuem para a manutenção dos trabalhos da escola e favorecem a ação no espaço educativo e social, sendo pertinente destacar que sem sua atuação seria difícil realizar um trabalho pedagógico satisfatório no contexto da escola pública. Assim, como chama atenção Barroso (1995), o vigilante, o merendeiro, o auxiliar de disciplina, o faxineiro são também considerados educadores e são responsáveis pela educação dos alunos que frequentam a instituição escolar. Nessa perspectiva,

Apesar de serem em menor número e, durante muito tempo, exercerem uma actividade desqualificada, os membros do pessoal não docente deverão integrar também as estruturas e as redes de participação da escola. Devem fazê-lo na sua qualidade de adultos com responsabilidades educativas e como técnicos de apoio logístico às actividades de ensino (BARROSO, 1995, p. 10).

Desse modo, é oportuno que os demais profissionais da educação participem do processo de decisão da escola, contribuindo nos aspectos pedagógico, administrativo e financeiro, pois eles estão no cotidiano da escola e têm uma visão ampla sobre as práticas na instituição escolar. É importante que esses profissionais sejam ouvidos e façam parte da organização escolar, mudando a lógica da hierarquia e rompendo com o paradigma de que apenas os docentes e gestores sabem o que é melhor para a educação.

A presença dos pais na escola é outro mecanismo de defesa por uma educação de qualidade, com a visão de atores que não estão no dia a dia, dentro da escola, mas que têm interesse na oferta de uma educação com oportunidades para todos. A discussão da presença dos pais na escola é relevante, visto que são agentes sociais que, se bem aproveitados, contribuirão no processo das decisões e das avaliações da instituição educativa. 
Barroso (1995, p. 14) destaca a presença dos pais na escola como um fenômeno que possibilita aos pais a integração na prática educativa, "como coeducadores que devem participar nas estruturas formais e informais de gestão quotidiana da escola, independentemente do direito que lhes assiste, sempre, de acompanhar a escolarização dos seus filhos e exercer o controlo democrático sobre o funcionamento da escola".

A participação dos alunos é um mecanismo necessário para a efetiva implementação da gestão democrática. Essa participação deve ser ativa, tendo representação favorável. e suas propostas têm de ser discutidas como uma oportunidade para o desenvolvimento das ações educativas. A cultura de participação e exposição das propostas dos alunos é um exercício que rompe com as práticas de gestão e políticas que não levam em consideração a opinião dos sujeitos a quem essas políticas destinam-se. Portanto,

[...] numa concepção pedagógica mais actualizada, os alunos são considerados, não como objectos da formação, mas como sujeitos da sua formação. Isto significa que as crianças e jovens que frequentam as nossas escolas não devem ser vistas como consumidoras passivas dos conhecimentos transmitidos pelos professores, mas sim como co-produtoras dos saberes, saberes fazeres e saberes ser, necessários ao seu crescimento e desenvolvimento (BARROSO, 1995, p. 11).

O papel dos alunos na política estabelecida no contexto da escola pública é significativo, pois se sentem importantes em meio às práticas educativas e envolvem-se com mais frequência na ação desenvolvida na escola, visto que participaram do processo de elaboração do que estão vivenciando e são coautores de políticas implementadas na instituição escolar. Sander (2005) salienta que as práticas e princípios que se referem à gestão democrática não vão existir nos espaços educativos como "passe de mágica", mas demandam tempo, experiências exitosas que mostrarão as práticas de escolas que trabalham numa perspectiva da participação e autonomia escolar. Todavia, "a consolidação da gestão democrática da educação é um desafio de grandes proporções, que implica uma filosofia política e uma estratégia de ação pedagógica" (SANDER, 2005, p. 136).

A presença dos vários segmentos nos processos políticos da escola pública favorece a constatação de princípios que são defendidos pelo modelo de gestão democrática, destacando-se a descentralização, a participação e a autonomia. A comunidade escolar e local também são consideradas como instâncias significativas para a concretização da gestão democrática, através do conselho escolar, adquirindo, assim, "novos aliados capazes de se engajarem na sua defesa, de se coligarem com os actores escolares e de ampliarem as suas vozes pedagógicas" (LIMA, 2006, p. 32) 


\section{Considerações finais}

As configurações das políticas educacionais atuais levam à compreensão de práticas educativas que viabilizam a gestão gerencial, especialmente, no decorrer dessas duas décadas de vigência da LDB/1996. O Estado, por meio de sua reestruturação, implementou políticas de avaliação em larga escala, evidenciando a eficiência, a eficácia e a produtividade, assim como o ranqueamento entre as escolas e tantos outros indicadores. para orientar o financiamento das políticas de educação ou, melhor, das políticas gerenciais de educação (HYPÓLITO, 2008).

As políticas gerenciais surgiram como meios de concretizar o sucesso escolar, tendo a qualidade da educação como ênfase no discurso da modernização da gestão pública gerencial. Outros princípios basilares são a ressignificação dada à descentralização, à autonomia e à participação, configurando-se em aspectos presentes nos acordos nacionais e internacionais para a concretização de uma escola autônoma, eficaz e eficiente, como preconiza a lógica do mercado a partir da última década do século XX. Nesse sentido, “[...] em todo o setor público, passa-se a admitir o modelo de gestão descentralizada, com participação dos usuários/clientes, que vão influenciar a formulação de propostas para o desenvolvimento da gestão educacional" (CASTRO, 2008, p. 392).

Os movimentos sociais e os educadores, no entanto, defendem uma educação pública, laica, inclusiva, democrática e referenciada socialmente, por meio da participação dos diferentes segmentos, da efetivação do conselho escolar autônomo e deliberativo, no qual se favoreça aprendizagens coletivas mediante a intervenção política, cultural, social e educacional na organicidade administrativa, pedagógica e financeira da escola pública. Nessa dimensão, "isto significa que os conceitos de autonomia, de descentralização e de participação devem ser entendidos em ruptura com o processo de ressemantização neoliberal que vem ocorrendo nas últimas décadas" (LIMA, 2006, p. 31).

Assim, mesmo tendo uma LDB/1996 que regulamenta a concepção de gestão que deve ser vivenciada nas escolas públicas - gestão democrática -, as políticas educacionais apresentam contradições ao evidenciar uma concepção de gestão na lógica empresarial - gestão gerencial -, com preceitos do mercado, acionando os diferentes participantes a competir, em detrimento da transformação da escola em espaço solidário, humanitário e congruente com práticas inclusivas. Eis, portanto, o desafio da educação!

Recebido em agosto de 2016 e aprovado em outubro de 2016 


\section{Referências}

BARROSO, João. O estudo da autonomia da escola: da autonomia decretada à autonomia construída. In: BARROSO, João. O estudo da Escola. Porto: Porto Editora, 1996.

BARROSO, João. Para o desenvolvimento de uma cultura de participação na escola. Editora: Instituto de Inovação Educacional, 1995.

BRASIL. Constituição Federal de 1988. Brasília, 1988.

BRASIL. Lei de Diretrizes e Bases da educação Nacional (1996). Biblioteca Digital da câmara dos deputados. Lei no 9.394 de 20 de dezembro de 1996.

BRASIL. Ministério da Educação. Instituto Nacional de Estudos e Pesquisas Educacionais (Inep). Avaliação do Plano Nacional de Educação: 2001/2008. Brasília, DF: MEC/Inep, 2010.

BRUEL, Ana Lorena de Oliveira. Políticas e legislação da educação básica no Brasil. Curitiba: Ibpex, 2010.

CABRAL NETO, Antônio. Gerencialismo e gestão educacional: cenários, princípios e estratégias. In: FRANÇA, Magna; BEZERRA, Maura Costa (org.). Política educacional: gestão e qualidade do ensino. Brasília: Liber livro, 2009.

CABRAL NETO, Antônio; CASTRO, Alda Maria Duarte Araújo. Gestão escolar em instituições de ensino médio: entre a gestão democrática e a gerencial. Educação e Sociedade, v. 32, n. 116, p. 745-770, jul./set. 2011.

CASASSUS, Juan. A centralização e a descentralização da educação. Caderno de Pesquisa. São Paulo, n. 95, p. 37-42, nov. 1995.

CASASSUS, Juan. Tarefas da educação. Campinas, SP: Autores Associados, 1995a.

CASTRO, Ana Paula Pádua Pires de. A gestão dos recursos financeiros e patrimoniais da escola. Curitiba: Ibpex, 2008.

CASTRO, Alda Maria Duarte Araújo. Administração gerencial: a nova configuração da gestão da educação na América Latina. Revista RBPAE. - v.24, n.3, p. 389-406, set./dez. 2008

CURY, Carlos Roberto Jamil. Gestão democrática dos sistemas públicos de ensino. In: OLIVEIRA, Maria Auxiliadora Monteiro (org.). Gestão educacional: novos olhares, novas abordagens. Petrópolis, RJ: Vozes, 2005.

DALBERIO, Maria Célia Borges. Neoliberalismo, políticas educacionais e a gestão democrática na escola pública de qualidade. São Paulo: Paulus, 2009.

DALE, Roger. Globalização e reavaliação da governação educacional: um caso de ectopia sociológica. In: TEODORO, Antônio; TORRES, Carlos Alberto (Orgs.). Educação Crítica \&Utopia: perspectivas para o século XXI. São Paulo: Cortez, 2006.

DOURADO, Luiz Fernandes. Plano Nacional de Educação (2011-2020): avaliação e perspectivas. Goiânia editora UFG; Belo Horizonte: Autêntica, 2011.

FRANÇA, Magna. Políticas de gestão e qualidade: desafios para educação básica. In: FRANÇA, Magna; BEZERRA, Maura Costa (org.). Política educacional: gestão e qualidade do ensino. Brasília: Liber livro, 2009. 
HORA, Dinair Leal da. Gestão democrática na escola: Artes e ofícios de participação coletiva. Campinas, SP: Papirus, 1994.

HYPÓLITO, Álvaro Moreira. Estado gerencial, reestruturação educativa e gestão da educação. Revista RBPAE - v. 24, n. 1, p. 63-78, jan./abr. 2008.

LIBÂNEO, José Carlos. Organização e gestão da escola: teoria e prática. Goiânia: Editora Alternativa, 2004.

LIMA, Lícinio C. Escolarizando para uma educação crítica: a reinvenção das escolas como organizações democráticas. In: TEODORO, Antônio; TORRES, Carlos Alberto (Orgs.). Educação Crítica \&Utopia: perspectivas para o século XXI. São Paulo: Cortez, 2006.

LÜCK, Heloísa. A gestão participativa na escola. Petrópolis, RJ; Vozes, 2010.

MINTO, Lalo Watanabe. A administração Escolar no contexto da nova república e do neoliberalismo. In: ADREOTTI, A. L.; LOMBARDI, J. C.; MINTO, L. W. História da administração Escolar no Brasil: do diretor ao gestor. Campinas, SP: Editora Alínea, 2010.

PARO, Vitor Henrique. Qualidade do Ensino: a contribuição dos pais. São Paulo: Xamã, 2007.

PAULA, Ana Paula Paes de. Administração pública brasileira entre o gerencialismo e a gestão social. RAE - DEBATE. Vol. 45, n.1, p. 36-49, jan./mar. 2005.

RODRIGUES, Neidson. Da mistificação da escola à escola necessária. São Paulo: Cortez, 1996.

SANDER, Benno. Políticas Públicas e Gestão Democrática da Educação. Brasília: Liber Livro Editora, 2005.

SILVA, Jair Militãoda.A autonomia da escola pública: A re-humanização da escola. Campinas, SP; Papirus, 1996.

SPÓSITO, Marília Pontes. Educação, gestão democrática e participação popular. In: BASTOS, João Baptista (org.). Gestão democrática. Rio de Janeiro: DP\&A: SEPE, 2005.

TAVARES, Maria das Graças Medeiros. Educação brasileira e negociação política: o processo constituinte de 1987 e a gestão democrática. Maceió: EDUFAL, 2003.

VIEIRA, Sofia Lerche. Políticas de formação em cenários de reforma. In: VEIGA, I. P. ; AMARAL, A. L. (Orgs.). Formação de professores: políticas e debates. Campinas: Papirus, 2012. 